\title{
Electrocardiographic Aspects of Singleton Pregnancy and Neonatal Period in American Miniature Horse Breed
}

\author{
Juliana Almeida Nogueira da Gama', Gabriela Amorim Campos' ${ }^{1}$ Raphael Tortorelli Teixeira', \\ Mirian Harumi Tsunemi' ${ }^{2}$, Bianca Paola Santarosa ${ }^{3}$, Henrique Barbosa Hooper ${ }^{4}$, \\ Maria Lúcia Gomes Lourenço' ${ }^{1}$ \& Simone Biagio Chiacchio' ${ }^{1}$
}

\begin{abstract}
Background: During pregnancy, cardiovascular adaptations occur in order to meet maternal demands and adequate support for fetal development, but they are still unclear in the equine species, especially in the American Miniature horse breed. The main hemodynamic changes that occur during pregnancy are increased heart rate, cardiac output, and blood volume. It is necessary to use the reference values for the miniature breeds, in addition to the age range and reproductive condition, so the objective of this study was to evaluate the effect of pregnancy on electrocardiographic (ECG) parameters in mares and also of age in newborns foals of American Miniature horse breed.

Materials, Methods \& Results: Ten American Miniature Horse mares, between 7 and 19 years old (12.14 \pm 4.05 years), $116.85 \pm 24.09 \mathrm{~kg}$ of body weight were used in the experiment. All these mares were pluriparous, with $5.9 \pm 3.5$ of births, minimum of 2, and maximum of 12 foaling times. They were maintained in common social group in an indoor house stable with straw bed, with access to an outdoor paddock for several h per day. Twice a day they were fed with hay. Mineral supplements and water were available ad libitum. The ECG were obtained in 10 pregnant mares and in 10 neonates. All females were examined at a representative time of each trimester of pregnancy, at 30,210, 300 days before and 21 days after delivery. Neonates were examined on different times: first $24 \mathrm{~h}$ after delivery, weekly on the 7th, 14th, 21st, 28th and 35th days of age. The ECG parameters considered were the heart rate and rhythm, duration and intervals (P, PR, QRS, QT, T) and amplitude $(\mathrm{P}, \mathrm{R}, \mathrm{S}, \mathrm{T})$ of ECG waves. The mean of pregnancy duration was $319.4 \pm 4.97$ days. Heart Rate (HR) varied between 51 to $59 \mathrm{bpm}$ during pregnancy and $56 \mathrm{bpm}$ on the $21 \mathrm{st}$ day after delivery. Comparing the clinical parameters of pregnant mares, non-pregnant mares and foal a difference was found for HR, Respiration Rate (RR) and Temperature $(P=0.001)$. All ECG parameters of pregnant, non-pregnant and foal mares showed a significant difference $(P=0.0001)$, except for the amplitude of the P1, P2 and R waves, which was similar for the 3 groups. The mean values of $\mathrm{HR}$ and amplitude of the positive T wave were higher in foals when compared to pregnant and non-pregnant mares, which in turn did not differ from each other. The mean duration of the $\mathrm{P}$ wave, PR segment, QRS complex, QT segment and T wave were the same among mares and greater than in foals. Comparing pregnant and non-pregnant mares, there was a difference in only 3 parameters: duration of the QTc segment, amplitude of the $\mathrm{S}$ wave and negative $\mathrm{T}$ wave. The non-pregnant mares had a longer duration of the QTc segment and a greater amplitude of the negative $\mathrm{T}$ wave, while the foals had a greater amplitude of the $\mathrm{S}$ wave.

Discussion: Although this study did not measure HR at delivery time, it is worth to consider the action of the parasympathetic autonomic nervous system close to delivery, which reduces the HR of mares. This is because at delivery, sympathetic-adrenal activation should be avoided since the increase in sympathetic tone can cause uterine atony via B2 receptors. For this reason, it has been shown that, during physiological birth, horses are under parasympathetic control, and stress response mechanisms are not activated. It was conclude that the morphometry of the waves, intervals and ECG complexes, during the evolution of the reproductive state, the electrocardiographic aspects were generally associated with heart rate (PR and QT intervals). As for neonates, there was a discrepancy among the most of ECG parameters when compared to the adult female, regardless of reproductive status, clarifying the importance of ECG patterns not only for the breed, but also for the age group.
\end{abstract}

Keywords: electrophysiology, heart rate, gestation, mares, neonatal foals. 


\section{INTRODUCTION}

During pregnancy, cardiovascular adaptations occur in order to meet maternal and fetal development demands [2], but they are still unclear in equine, especially in the American Miniature Horse (AMH) breed. The main hemodynamic changes are increased heart rate (HR), cardiac output, and blood volume $[1,12,13,23]$.

The electrocardiography (ECG), with HR assessment and wave morphology [19], can assist in complete cardiac evaluation of pregnant mares and newborn foals [4], however, it is necessary to use the reference values for the miniature breeds, in addition to the age range and reproductive condition [6,7,14,24,25].

The ECG exams of 66 AMH mares in the initial third of the pregnancy showed few changes in relation to non-pregnant females, but the authors suggested progressive supervision on gestational period in order to elucidate the manifestations in ECG patterns [24].

Although widely used in the small animal internal medicine [27], studies on ECG in equine and foal fetuses are scarce. This exam can be an important tool in equine neonatology [12], as it is an accessible, non-invasive and easily performed technique in the field [24]. Several studies had been carried out in relation to ECG and other clinical parameters in foals, such as Thoroughbred [5,20,28] and Ponies [10]. However, there are no descriptions of clinical parameters and ECG of AMH neonatal foals, despite the study that evaluated 17 foals aged 15 days to 10 months [25].

The aim of this study was to evaluate and describe the ECG and clinical parameters of AMH mares throughout the 3 trimesters of pregnancy and in the postpartum period, and the newborn foals from birth to the 35 th days of life.

\section{MATERIALS AND METHODS}

\section{Animals}

The experiment was performed at "Água Azul" farm, located in Dois Córregos city, in São Paulo State, Brazil. This farm started the creation of American Miniature horse breed in 1982, and since then has participated in agricultural exhibitions and has a herd of about 70 animals.

Ten American Miniature Horse mares, between 7 and 19 years old $(12.14 \pm 4.05$ years $), 116.85 \pm 24.09$ $\mathrm{kg}$ of body weight were used in the experiment. All these mares were pluriparous, with $5.9 \pm 3.5$ of births, minimum of 2 , and maximum of 12 foaling times. They were maintained in common social group in an indoor house stable with straw bed, with access to an outdoor paddock for several $h$ per day. Twice a day they were fed with hay. Mineral supplements and water were available ad libitum.

Prior to the study, all animals were subjected to a clinical examination of a general physical examination, that included assessment of mucosa, degree of hydration, capillary refilling time, lymph nodes examination, arterial pulse, measurement of the heart rate and respiratory frequency, evaluation of intestinal motility, discharge of the ileocecal valve and rectal temperature. Moreover, there was an evaluation of the clinical history, including any previous diseases and pregnancy history.

\section{Experimental design}

In the experiment was included a group of 10 healthy pregnant mares at gestational stages between 1 and 11 months. All of the animals were evaluated for the presence of heart disease by cardiac auscultation. The main exclusion criterion of this study was the presence of altered cardiac auscultation signs, such as a cardiac murmur or arrhythmia.

The mares were accompanied during 11 months of gestation by choosing a representative time point of each trimester of pregnancy. In the mares, ECG recordings, clinical examination and measurement of systolic blood pressure by Doppler method were obtained on days $30^{\text {th }}, 210^{\text {th }}$ and $300^{\text {th }}$ of pregnancy and $21^{\text {st }}$ days after delivery (Tables $1 \& 2$ ). The same examinations were performed in the neonates at $24 \mathrm{~h}$ after delivery, and later at $7^{\text {th }}, 14^{\text {th }}, 21^{\text {st }}, 28^{\text {th }}$ and $35^{\text {th }}$ days of life (Table 3).

For comparing the clinical and electrocardiographic data of pregnant mares (one to 11-months of pregnancy), non-pregnant mares (one to 35 days after foaling), and foals (one to 35 days of life), the mean of time points were performed (Tables $4 \&$ Table 5).

\section{Electrocardiography examination}

To obtain the electrocardiograms, computerized device equipped with an ECG Acquisition Module for Computer, PC-ECG version $2.0^{1}$ was used. The maternal and neonatal records in the morning, in a closed 
environment (individual stall), free of external stimulus to avoid consequent tachycardia were performed. During the recordings, the mares remained in their normal surroundings, and neonates were kept close to their mothers in order to avoid stress and tachycardia. The floor was covered with rubber plates in order to avoid interferences in the electrocardiographic tracing. The animals were maintained in the station in the standing position with limbs parallel to each other and without any sedation, tranquilizers or anesthesia. The results of the tracings were not correlated with the individual weight of each animal.

ECG tracing was sequentially performed on each horse (mare and neonate foal) from the bipolar base-apex lead system. The electrodes were positioned with the yellow electrode on the left side above the cardiac apex immediately behind the olecranon bone. The red electrode on the right side, cranial to the scapula and near the jugular vein, with the ground electrode attached to the withers [21].
Traces were obtained at a rate of $25 \mathrm{~mm} / \mathrm{s}$, with the sensitivity set to $1 \mathrm{~cm}=1$ millivolt $(\mathrm{mV})$ per minute, to analyze at least 10 complexes per electrocardiogram. For each electrocardiographic recording, the respiratory frequency, heart rate (HR), morphology and duration of the P, R and T waves, QRS complex, PR and QT intervals (seconds), amplitude of the P, $\mathrm{R}, \mathrm{T}$ and $\mathrm{S}$ waves $(\mathrm{mV})$ and the ST segment (normal, elevated or depressed) and polarity of the T wave (positive, negative or biphasic) were obtained.

\section{Statistical analysis}

The assumption of normality of each parameter was evaluated by the Kolmogorov-Smirnov test, and descriptive statistics such as mean and standard deviation were calculated for each time point. Data were analyzed by ANOVA and mixed models analysis of the $\mathrm{R}$ program. Time was used as a repeated effect, and animal as random effect Multiple comparisons among consecutive time points were held and significant cases were registered for $P<0.05$.

Table 1. Means and standard deviation of clinical parameters of 10 American Miniature Horse breed mares during the trimesters of pregnancy (30, 210 and 300 days) and 21 days after delivery.

\begin{tabular}{|c|c|c|c|c|c|}
\hline & \multicolumn{3}{|c|}{ During pregnancy } & \multirow{2}{*}{$\frac{\text { After delivery }}{21 \text { days }}$} & \multirow{2}{*}{$P$-value } \\
\hline & 30 days & 210 days & 300 days & & \\
\hline HR (bpm) & $52.00 \pm 8.33^{\mathrm{a}}$ & $44.8 \pm 10.29^{b}$ & $57.43 \pm 11^{\mathrm{a}}$ & $52.4 \pm 7.11^{\mathrm{a}}$ & 0.034 \\
\hline $\mathrm{RR}$ (mpm) & $31.14 \pm 19.39$ & $28.4 \pm 4.4$ & $28 \pm 7.66$ & $24.4 \pm 8.98$ & 0.07 \\
\hline $\mathrm{T}\left({ }^{\circ} \mathrm{C}\right)$ & $37.19 \pm 0.56$ & $36.75 \pm 0.73$ & $37.01 \pm 0.92$ & $37.24 \pm 0.73$ & 0.07 \\
\hline $\mathrm{SBP}(\mathrm{mmHg})$ & $105.71 \pm 18.13$ & $118.5 \pm 33.25$ & $97.86 \pm 12.2$ & $108.5 \pm 33.25$ & 0.27 \\
\hline
\end{tabular}

HR: heart rate; RR: respiration rate; $\mathrm{T}^{\circ} \mathrm{C}$ : temperature; SBP: systolic blood pressure. Means followed by different lowercase letter in the column differed statistically $(P<0.05)$.

Table 2. Means and standard deviation of electrocardiographic parameters of 10 American Miniature Horse breed mares during the trimesters of pregnancy (30, 210 and 300 days) and 21 days after delivery.

\begin{tabular}{|c|c|c|c|c|c|}
\hline & \multicolumn{3}{|c|}{ During pregnancy } & \multicolumn{2}{|l|}{ After delivery } \\
\hline & 30 days & 210 days & 300 days & 21 days & $P$-value \\
\hline HR (bpm) & $51.00 \pm 9.52^{\mathrm{a}}$ & $46.70 \pm 6.70^{\mathrm{b}}$ & $59.71 \pm 9.12^{\mathrm{bc}}$ & $56.7 \pm 8.47^{\mathrm{ac}}$ & 0.006 \\
\hline $\mathrm{P}(\mathrm{ms})$ & $81.43 \pm 10.63^{\mathrm{a}}$ & $77 \pm 14.18^{\mathrm{a}}$ & $81.43 \pm 9^{\mathrm{a}}$ & $80 \pm 12.47^{\mathrm{a}}$ & 0.70 \\
\hline PR (ms) & $171.43 \pm 28.54^{\mathrm{a}}$ & $182 \pm 26.58^{b}$ & $152.86 \pm 20.59^{\mathrm{ab}}$ & $167 \pm 30.57^{\mathrm{ab}}$ & 0.003 \\
\hline QRS (ms) & $82.86 \pm 7.56^{\mathrm{a}}$ & $82.00 \pm 7.89^{\mathrm{a}}$ & $84.29 \pm 9.76^{\mathrm{a}}$ & $85.00 \pm 8.5^{\mathrm{a}}$ & 0.84 \\
\hline QT (ms) & $451.43 \pm 41.40^{\mathrm{a}}$ & $467.00 \pm 29.46^{\mathrm{b}}$ & $412.86 \pm 44.24^{\mathrm{ab}}$ & $431.00 \pm 41.22^{\mathrm{ab}}$ & 0.007 \\
\hline QTc (ms) & $415.71 \pm 16.18^{\mathrm{a}}$ & $405.00 \pm 25.50^{\mathrm{a}}$ & $405.71 \pm 12.72^{\mathrm{a}}$ & $420.00 \pm 34.96^{\mathrm{a}}$ & 0.11 \\
\hline $\mathrm{T}(\mathrm{ms})$ & $16.000 \pm 19.15^{\mathrm{a}}$ & $160.00 \pm 27.08^{\mathrm{a}}$ & $130.00 \pm 21.60^{\mathrm{a}}$ & $141.00 \pm 19.69^{\mathrm{a}}$ & 0.21 \\
\hline $\mathrm{P} 1(\mathrm{mV})$ & $0.08 \pm 0.04^{\mathrm{a}}$ & $0.08 \pm 0.02^{\mathrm{a}}$ & $0.06 \pm 0.02^{\mathrm{a}}$ & $0.11 \pm 0.05^{\mathrm{a}}$ & 0.4664 \\
\hline $\mathrm{P} 2(\mathrm{mV})$ & $0.21 \pm 0.05^{\mathrm{a}}$ & $0.22 \pm 0.07^{\mathrm{a}}$ & $0.19 \pm 0.03^{\mathrm{a}}$ & $0.23 \pm 0.05^{\mathrm{a}}$ & 0.09964 \\
\hline $\mathrm{R}(\mathrm{mV})$ & $0.04 \pm 0.02^{\mathrm{a}}$ & $0.03 \pm 0.04^{\mathrm{a}}$ & $0.05 \pm 0.04^{\mathrm{a}}$ & $0.05 \pm 0.04^{\mathrm{a}}$ & 0.14 \\
\hline $\mathrm{S}(\mathrm{mV})$ & $1.48 \pm 0.33^{\mathrm{ab}}$ & $1.11 \pm 0.19^{\mathrm{b}}$ & $1.29 \pm 0.17^{\mathrm{a}}$ & $1.46 \pm 0.26^{\mathrm{a}}$ & $<0.0001$ \\
\hline $\mathrm{T}-(\mathrm{mV})$ & $1.09 \pm 0.43^{\mathrm{ab}}$ & $0.73 \pm 0.36^{\mathrm{a}}$ & $0.73 \pm 0.43^{\mathrm{ab}}$ & $1.10 \pm 0.6^{\mathrm{b}}$ & 0.0028 \\
\hline $\mathrm{T}_{+}(\mathrm{mV})$ & $0.04 \pm 0.05^{\mathrm{a}}$ & $0.04 \pm 0.03^{\mathrm{a}}$ & $0.11 \pm 0.08^{\mathrm{a}}$ & $0.01 \pm 0.11^{\mathrm{a}}$ & 0.29 \\
\hline
\end{tabular}

Means followed by different lowercase letter in the column differed statistically $(P<0.05)$. 
J.A.N. Gama, G.A. Campos, R.T. Teixeira, et al. 2021. Electrocardiographic Aspects of Singleton Pregnancy and Neonatal Period in American Miniature Horse Breed.

Acta Scientiae Veterinariae. 49: 1806.

Table 3. Means and standard deviation of the electrocardiographic parameters of 10 American Miniature Horse breed foals over time, from the first to the 35 th day of life.

\begin{tabular}{|c|c|c|c|c|c|c|c|}
\hline & \multicolumn{6}{|c|}{ Days of life } & \multirow{2}{*}{$P$-value } \\
\hline & $1^{\mathrm{st}}$ & $7^{\text {th }}$ & $14^{\text {th }}$ & $21^{\text {th }}$ & $28^{\text {th }}$ & $35^{\text {th }}$ & \\
\hline HR (bpm) & $107.50 \pm 15.16$ & $107.10 \pm 18.72$ & $112.40 \pm 24.23$ & $117.50 \pm 19.20$ & $112.40 \pm 31.72$ & $98.30 \pm 23.73$ & 0.190 \\
\hline $\mathrm{P}(\mathrm{ms})$ & $57 \pm 9.35$ & $55.2 \pm 13.38$ & $58.3 \pm 13.82$ & $56 \pm 12.19$ & $56.5 \pm 11.87$ & $58.8 \pm 13.03$ & 0.891 \\
\hline PR (ms) & $109.8 \pm 13.75$ & $101.3 \pm 18.56$ & $104.4 \pm 28.64$ & $104.1 \pm 18.63$ & $105.3 \pm 21.52$ & $108.1 \pm 14.63$ & 0.710 \\
\hline QRS (ms) & $58.9 \pm 5.38$ & $58.5 \pm 5.38$ & $63.2 \pm 11.05$ & $60.5 \pm 7.62$ & $63 \pm 13.57$ & $65.7 \pm 9.74$ & 0.148 \\
\hline QT (ms) & $289.6 \pm 31.9$ & $269.1 \pm 32.56$ & $274.4 \pm 31.77$ & $263.1 \pm 42.57$ & $274.1 \pm 44.48$ & $296.2 \pm 42.75$ & 0.116 \\
\hline $\mathrm{QTc}(\mathrm{ms})$ & $380.8 \pm 22.84$ & $357.5 \pm 18.86$ & $370.4 \pm 25.79$ & $364 \pm 34.35$ & $365.3 \pm 29.98$ & $371.7 \pm 31.16$ & 0.363 \\
\hline $\mathrm{T}(\mathrm{ms})$ & $90.6 \pm 21.43$ & $92.40 \pm 18.53$ & $99.1 \pm 24.52$ & $78.4 \pm 31.94$ & $98.5 \pm 26.22$ & $104 \pm 32.07$ & 0.188 \\
\hline $\mathrm{P} 1(\mathrm{mV})$ & $0.17 \pm 0.07$ & $0.13 \pm 0.03$ & $0.11 \pm 0.05$ & $0.11 \pm 0.03$ & $0.09 \pm 0.05$ & $0.12 \pm 0.06$ & 0.033 \\
\hline $\mathrm{P} 2(\mathrm{mV})$ & $0.27 \pm 0.07$ & $0.28 \pm 0.08$ & $0.26 \pm 0.09$ & $0.21 \pm 0.08$ & $0.21 \pm 0.08$ & $0.22 \pm 0.08$ & 0.038 \\
\hline $\mathrm{R}(\mathrm{mV})$ & $0.06 \pm 0.04$ & $0.07 \pm 0.06$ & $0.05 \pm 0.03$ & $0.08 \pm 0.06$ & $0.06 \pm 0.02$ & $0.05 \pm 0.03$ & 0.432 \\
\hline $\mathrm{S}(\mathrm{mV})$ & $2.48 \pm 0.31$ & $2.67 \pm 0.75$ & $2.45 \pm 0.79$ & $2.23 \pm 0.83$ & $2.24 \pm 0.77$ & $2.20 \pm 0.8$ & 0.237 \\
\hline $\mathrm{T}-(\mathrm{mV})$ & $0.30 \pm 0.15$ & $0.28 \pm 0.28$ & $0.57 \pm 0.31$ & $0.47 \pm 0.38$ & $0.48 \pm 0.14$ & $0.64 \pm 0.33$ & 0.072 \\
\hline $\mathrm{T}+(\mathrm{mV})$ & $0.18 \pm 0.15$ & $0.25 \pm 0.16$ & $0.37 \pm 0.37$ & $0.36 \pm 0.29$ & $0.30 \pm 0.35$ & $0.19 \pm 0.15$ & 0.156 \\
\hline
\end{tabular}

Table 4. Means and standard deviation of clinical parameters of 10 pregnant, non-pregnant mares and foals of American Miniature Horse breed.

\begin{tabular}{ccccc}
\hline & Pregnant mares & Non-pregnant mares & Neonatal foals & $P$-value \\
\hline HR $(\mathrm{bpm})$ & $51.14 \pm 8.73^{\mathrm{a}}$ & $50.71 \pm 8.51^{\mathrm{a}}$ & $99.91 \pm 18.61^{\mathrm{b}}$ & 0.0001 \\
$\mathrm{RR}(\mathrm{mpm})$ & $30.62 \pm 10.35^{\mathrm{a}}$ & $25.21 \pm 8.73^{\mathrm{b}}$ & $61.26 \pm 26.24^{\mathrm{ac}}$ & 0.0001 \\
$\mathrm{~T}\left({ }^{\circ} \mathrm{C}\right)$ & $37.00 \pm 0.90^{\mathrm{a}}$ & $37.22 \pm 0.66^{\mathrm{a}}$ & $38.63 \pm 0.50^{\mathrm{b}}$ & 0.0001 \\
$\mathrm{SBP}(\mathrm{mmHg})$ & $105.17 \pm 22.13^{\mathrm{a}}$ & $102.08 \pm 20.09^{\mathrm{a}}$ & $107.66 \pm 14.65^{\mathrm{a}}$ & 0.327 \\
\hline
\end{tabular}

HR: heart rate; RR: respiration rate; T: temperature; SBP: systolic blood pressure. Means followed by different lowercase letter in the column differed statistically $(P<0.05)$.

Table 5. Means and standard deviation of electrocardiographic parameters of 10 pregnant, non-pregnant mares and foals of American Miniature Horse breed.

\begin{tabular}{ccccc}
\hline & Pregnant mare & Non-pregnant mare & Neonatal foals & $P$-value \\
\hline HR (bpm) & $51.14 \pm 8.73^{\mathrm{a}}$ & $53.53 \pm 8.48^{\mathrm{a}}$ & $109.20 \pm 22.59^{\mathrm{b}}$ & 0.0001 \\
P (ms) & $81.94 \pm 12.21^{\mathrm{a}}$ & $83.66 \pm 12.88^{\mathrm{a}}$ & $56.96 \pm 11.89^{\mathrm{b}}$ & 0.0001 \\
PR (ms) & $176.01 \pm 26.91^{\mathrm{a}}$ & $171.50 \pm 31.66^{\mathrm{a}}$ & $105.50 \pm 17.27^{\mathrm{b}}$ & 0.0001 \\
QRS (ms) & $83.20 \pm 8.88^{\mathrm{a}}$ & $81.83 \pm 7.24^{\mathrm{a}}$ & $61.63 \pm 9.25^{\mathrm{b}}$ & 0.0001 \\
QT (ms) & $445.92 \pm 38.33^{\mathrm{a}}$ & $446.66 \pm 42.09^{\mathrm{a}}$ & $277.75 \pm 38.24^{\mathrm{b}}$ & 0.0001 \\
QTc (ms) & $406.60 \pm 26.80^{\mathrm{a}}$ & $419.33 \pm 30.58^{\mathrm{b}}$ & $328.45 \pm 112.66^{\mathrm{ac}}$ & 0.0001 \\
T (ms) & $147.96 \pm 26.39^{\mathrm{a}}$ & $143.66 \pm 22.47^{\mathrm{a}}$ & $93.83 \pm 26.45^{\mathrm{b}}$ & 0.0001 \\
P1 (mV) & $0.09 \pm 0.095^{\mathrm{a}}$ & $0.09 \pm 0.04^{\mathrm{a}}$ & $0.12 \pm 0.05^{\mathrm{a}}$ & 0.3943 \\
P2 (mV) & $0.21 \pm 0.05^{\mathrm{a}}$ & $0.22 \pm 0.04^{\mathrm{a}}$ & $0.23 \pm 0.08^{\mathrm{a}}$ & $0.06 \pm 0.04^{\mathrm{a}}$ \\
R (mV) & $0.03 \pm 0.03^{\mathrm{a}}$ & $0.04 \pm 0.03^{\mathrm{a}}$ & $2.37 \pm 0.71^{\mathrm{ac}}$ & 0.1806 \\
S (mV) & $1.20 \pm 0.26^{\mathrm{a}}$ & $1.46 \pm 0.23^{\mathrm{b}}$ & $0.44 \pm 0.28^{\mathrm{ac}}$ & 0.0001 \\
T $-(\mathrm{mV})$ & $0.78 \pm 0.34^{\mathrm{a}}$ & $1.07 \pm 0.50^{\mathrm{b}}$ & $0.27 \pm 0.26^{\mathrm{b}}$ & 0.0001 \\
T +(mV) & $0.06 \pm 0.04^{\mathrm{a}}$ & $0.05 \pm 0.04^{\mathrm{a}}$ & 0.0008 \\
\hline
\end{tabular}

Means followed by different lowercase letter in the column differed statistically $(P<0.05)$. 


\section{RESULTS}

The physical examination of the mares and foals showed normal vital parameters. Cardiorespiratory auscultation was normal in all horses, and the presence of altered breathing sounds, murmur or arrhythmias was not found in any animal. The mean of duration of pregnancy was $319.4 \pm 4.97$ days, with a minimum of 316 and a maximum of 328 days.

The predominant cardiac rhythm throughout pregnancy was sinus, with variable frequencies between sinus rhythm, sinus arrhythmia and sinus tachycardia, according to the proximity of delivery. During the neonatal period, there was a predominance of sinus rhythm and sinus tachycardia at 21 days of age and presence of sinus arrhythmia after 28 days.

Regarding the clinical parameters of the mares (Table 1), during the trimesters of pregnancy and 21 days postpartum, there was a statistical difference only for HR $(P<0.05)$, which was lower at 210 days, and similar in the others time points (30 and 300 days of pregnancy, and 21 postpartum).

In the ECG parameters of the mares (Table 2) there was a statistical difference in $\operatorname{HR}(P<0.01)$, duration of the PR interval $(P<0.01)$, QT $(P<0.01)$; and amplitude of the $\mathrm{S}(P<0.0001)$ and $\mathrm{T}$ wave $(P$ $<0.01)$. There was a decrease in HR comparing the beginning of pregnancy (30 days) with 210 days, an increase in relation to 300 days, and maintenance in the evaluated postpartum time point (21 days). Regarding the duration of the PR and QT segments, both showed the same behavior, with the highest values found at 210 days of gestation, the lowest at 30 days. While at the time points 300 days and 21 days postpartum, they were similar to the first two. The amplitude of the $\mathrm{S}$ wave showed similarity between 300 days of gestation and 21 days postpartum, and were greater compared to 210 days, even though at 30 days the mean was similar to the other analyzed times. The amplitude of the negative $\mathrm{T}$ wave was higher at 21 days postpartum, and less at 210 days of gestation, whereas the values at 30 days and 300 days of gestation were similar to the others.

The ECG parameters of the foals (Table 3) were similar among the time points analyzed, except for the amplitudes of waves P1 $(P<0.05)$ and P2 $(P<$ $0.05)$, which were statistically relevant. Numerically, it was possible to observe that in the P1 wave, on the first day of life the foals had a higher mean compared to the seven, 14, 21, 28 and 35 days, with the lowest ampli- tude being seen on the 28th day. The $\mathrm{P} 2$ wave showed numerical similarity between the first 14 days of life $\left(1^{\text {st }}, 7^{\text {th }}\right.$ and $\left.14^{\text {th }}\right)$, and then between $21^{\text {st }}$ and $35^{\text {th }}$ day.

Comparing the clinical parameters of pregnant mares, non-pregnant mares and foal (Table 4), a difference was found for HR, RR and TC $(P=0.001)$. The mean values of HR and TC had behaved in the same way, being higher in foals and similar between pregnant and non-pregnant mares. RR was higher in foals, followed by pregnant mares and lower in nonpregnant mares.

All ECG parameters of pregnant, non-pregnant and foal mares (Table 5) showed a significant difference $(P=0.0001)$, except for the amplitude of the P1, P2 and $\mathrm{R}$ waves, which was similar in the 3 groups. The mean values of $\mathrm{HR}$ and amplitude of the positive $\mathrm{T}$ wave were higher in foals when compared to pregnant and non-pregnant mares, which in turn did not differ from each other. The mean duration of the $\mathrm{P}$ wave, PR segment, QRS complex, QT segment and T wave were the same among mares and greater than in foals. Comparing pregnant and non-pregnant mares, there was a difference in only 3 parameters: duration of the QTc segment, amplitude of the $\mathrm{S}$ wave and negative $\mathrm{T}$ wave. The non-pregnant mares had a longer duration of the QTc segment and a greater amplitude of the negative $\mathrm{T}$ wave, while the foals had a greater amplitude of the $\mathrm{S}$ wave.

\section{DISCUSSION}

The HR of mares at 210 days was considerably lower than the other measurements, due to the greater gestational volume found in this period. However, at the end of pregnancy (at 300 days), the values were higher in relation to the beginning at 30 days, corroborating with other studies with horses $[13,15$ 18,26]. Changes in the cardiovascular system and water balance have already been reported in women [8] and female rats [3]. In humans, vasodilatation occurs in the second month of pregnancy, and require additional adaptation processes, such as the increase of blood volume stimulated by the renin-angiotensinaldosterone system and increased heart rate [11]. These changes cause an increase in cardiac output, which had promoted an adequate perfusion of the pregnant uterus. In mares, an exponential increase in uterine perfusion during pregnancy has been described and 
is largely attributed to the increase in the diameter of uterine blood vessels [9].

Although this study did not measure HR at delivery time, it is worth to consider the action of the parasympathetic autonomic nervous system close to delivery, which reduces the HR of mares [16]. This is because at delivery, sympathetic-adrenal activation should be avoided since the increase in sympathetic tone can cause uterine atony via $\mathrm{B} 2$ receptors. For this reason, it has been shown that, during physiological birth, horses are under parasympathetic control, and stress response mechanisms are not activated. The release of cortisol during and after delivery is probably part of the endocrine pathways that regulate delivery and not a stress response associated with work [16].

As was found in this study, at 21 days postpartum, immediately after the foal's expulsion, the maternal HR decreased to values of non-pregnant mares. The HR mean of mares during foaling is much lower than the HR in horses in stressful situations, such as weaning, equestrian performances or deep exercises with HRs above 200 bpm [16].

In general, the HR and RR of the mares in this study showed means above the reference standard for the equine species: HR: 28 to $40 \mathrm{bpm}$; RR: 8 to 16 mpm [22]. However, they were numerically similar to the HR means of American Miniature Horse mares pregnant in the early third of gestation $(60.5 \pm 1.9$ bpm) and non-pregnant $(63.2 \pm 1.8 \mathrm{bpm})$ described by Santarosa et al. [25]. This difference in the HR and RR values obtained compared to normal for horses can be attributed to the miniature size of this breed under study. Body temperature means were below normal for adult horses $\left(37.5\right.$ to $\left.38.5^{\circ} \mathrm{C}\right)$, although close to the lower limit [22].

The measurement of the systolic blood pressure (SBP) of the mares in this study, although without statistical significance, showed a decrease at the end of gestation (at 300 days), which corroborated with ten Warmblood mares [17]. These authors studied the last 3 months of pregnancy, and found the highest SBP values at 275 days of gestation, and the lowest 3 days before delivery, then the SBP increased and remained constant until 3 days postpartum. These finding was like the present study, when the SBP at 21 days postpartum was similar to the beginning of pregnancy.

In mares, the duration of PR and QT intervals were inversely proportional to the HR, with higher values at 210 days of gestation and shorter at 30 days. Unlike this study, pregnant mares of the American Miniature Horse breed had shown no difference in relation to non-pregnant mares for the duration of these segments, in none of the 7 derivations, however, as already exposed, these animals presented themselves at the beginning of pregnancy [25].

The amplitude of the $\mathrm{S}$ wave was not influenced by the reproductive state, since at 210 days it was significantly lower, but at 300 days and 21 days postpartum the values were the same. The negative $\mathrm{T}$ wave showed distinct values between the mare in the postpartum period (21 days) and in the middle third of gestation (210 days). These ECG parameters also showed no difference between pregnant and nonpregnant mares of the same breed studied [25].

On the neonatal foals, the ECG parameters had shown a difference from the first to the 35 th day of life exclusively in terms of the amplitude of the $\mathrm{P}$ wave, which was bifid in these animals. It can be noted that the values of both P1 and P2 decreased as age progress. At 14th days of age, the values found for this parameter were similar to foals from 15 days to 10 months of age of the same breed [24].

Comparing the HR values of the American Miniature foals with Ponies [10], a similarity was noted, since the present study and the other authors had not found statistical difference in the analyzed period. However, comparing the duration of the PR segment and the QRS complex, numerically, the neonates in the present study had shorter time compared to the Ponies [10]. As for the duration of the $\mathrm{T}$ wave, the foals had presented lower values than those already described, which it is possibly due to the heterogeneous age of the foals [24].

In comparison of pregnant, non-pregnant mares and neonates, changes were observed in terms of reproductive status and also in terms of age in the vast majority of clinical and electrocardiographic parameters, in agreement with the data obtained in previous studies with the same breed [24,25]. Therefore, the findings of the newborns and healthy pregnant mares of the present study can be used as reference values for the breed, regarding the age and gestational days.

\section{CONCLUSIONS}

In this study it was conclude that the morphometry of the waves, intervals and electrocardiographic 
complexes, during the evolution of the reproductive state, the electrocardiographic aspects were generally associated with heart rate (PR and QT intervals). As for neonates, there was a discrepancy among the most of the electrocardiographic parameters when compared to the adult female, regardless of reproductive status, clarifying the importance of electrocardiographic patterns not only for the breed, but also for the age group.

\section{MANUFACTURER}

${ }^{1}$ Tecnologia Eletrônica Brasileira Ltda. São Paulo, SP, Brazil.
Acknowledgements. The authors thank the owner of "Água Azul" farm, José Eden Matosinho, located in Dois Córregos city, in São Paulo State, for his assistance and animals use.

Ethical approval. This study was approved by the Ethics Committee on Animal Use (CEUA) from the School of Veterinary Medicine and Animal Science (FMVZ) of São Paulo State University (UNESP), Botucatu Campus (under protocol $\mathrm{n}^{\circ}$ 122/2015).

Declaration of interest. The authors report no conflicts of interest. The authors alone are responsible for the content and writing of paper.

\section{REFERENCES}

1 Abbas A.E., Lester S.J. \& Connolly H. 2005. Pregnancy and the cardiovascular system. Internacional Journal of Cardiology. 98: 179-189. DOI: 10.1016/j.ijcard.2003.10.028

2 Adams-Brendemuehl C. \& Pipers F.S. 1987. Antepartum evaluations of equine fetus. Journal of Reproduction and Fertility. 35(Supplement): 565-573.

3 Atherton J.C., Dark J.M., Garland H.O., Morgan M.R., Pidgeon J. \& Soni S. 1982. Changes in water and electrolyte balance, plasma volume and composition during pregnancy in the rat. Journal of Physiology. 330: 81-93. DOI: 10.1113/jphysiol.1982.sp014330

4 Baska-Vincze B., Baska F. \& Szenci O. 2015. Fetal Heart Rate and Fetal Heart Rate Variability in Lipizzaner Broodmares. Acta Veterinaria Hungarica. 66: 89-99. DOI: 10.1556/AVet.2015.007

5 Bazzano M., Giuduce E., Di Pietro S. \& Piccione G. 2014. Vital Parameters in Newborn Thoroughbred foals during the first week of life. Internacional Journal of Anesthesiology Research. 2: 27-30. DOI: 10.14205/2310-9394.2014.02.02.1

6 Buss D.D., Rwalings C.A. \& Bisgard G.E. 1975. The normal electrocardiogram of the domestic pony. Journal of Electrocardiology. 8: 167-172. DOI: 10.1016/s0022-0736(75)80025-2

7 Dantas G.N., Lourenço M.L.G., Santarosa B.P., Ulian C.M.V., Heckler M.C.T., Carvalho L.R. \& Chiacchio S.B. 2015. Electrocardiographic methods in equines American Miniature Horse. Ciência Rural. 45: 848-853. DOI: 10.1590/0103-8478cr20140584.

8 Hunter S. \& Robson S.C. 1992. Adaptation of the maternal heart in pregnancy. British Heart Journal. 68: 540-543. DOI: $10.1136 / \mathrm{hrt} .68 .12 .540$

9 Klewitz J., Struebing C., Rohn K., Goergens A., Martinsson G., Orgies F., Probst J., Hollinshead F., Bollwein H. \& Sieme H. 2015. Effects of age, parity, and pregnancy abnormalities on foal birth weight and uterine blood flow in the mare. Theriogenology. 83: 721-729. DOI: 10.1016/j.theriogenology.2014.11.007

10 Lombard C.W., Evans M., Martin L. \& Tehrani J. 1984. Blood pressure, electrocardiogram and echocardiogram measurements in the growing pony foal. Equine Veterinary Journal. 16: 342-347. DOI: 10.1111/j.2042-3306.1984. tb01939.x

11 Lumbers E.R. \& Pringle K.G. 2014. Roles of the circulating renin-angiotensina-aldosterone system in human pregnancy. American Journal of Physiology-Regulatory, Integrative and Comparative Physiology. 306: 91-101. DOI: 10.1152/ajpregu.00034.2013

12 Matsui K., Sugano S. \& Masuyama I. 1985. Changes in the fetal heart rate of Thoroughbred horse through the gestation. The Japanese Journal of Veterinary Science. 47: 597-601. DOI: 10.1292/jvms1939.47.597

13 Nagel C., Aurich J. \& Aurich C. 2010. Determination of heart rate and heart rate variability in the equine fetus by fetus maternal electrocardiography. Theriogenology. 73: 973-983. DOI: 10.1016/j.theriogenology.2009.11.026

14 Nagel C., Aurich J., Palm F. \& Aurich C. 2011. Heart rate and heart rate variability in pregnant Warm blood and Shetland mares as well as their fetuses. Animal Reproduction Science. 127: 183-187. DOI: 10.1016/j.anireprosci.2011.07.021

15 Nagel C., Erber R., Bergmaier C., Wulf M., Aurich J., Möstl E. \& Aurich C. 2012. Cortisol and progestin release, heart rate and heart rate variability in the pregnant and postpartum mare, fetus and newborn foal. Theriogenology. 78: 759-767. DOI: 10.1016/j.theriogenology.2012.03.023 
16 Nagel C., Erber R., Ille N., von Lewinski M., Aurich J., Möstl E. \& Aurich C. 2014. Parturition in horses is dominated by parasympathetic activity of the autonomous nervous system. Theriogenology. 82(1): 160-168. DOI: 10.1016/j. theriogenology.2014.03.015

17 Nagel C., Trenk L., Aurich J., Wulf M. \& Aurich C. 2016. Changes in blood pressure, heart rate, and blood profile in mares during the last 3 months of gestation and the peripartum period. Theriogenology. 86: 1856-1864. DOI: 10.1016/j. theriogenology.2016.06.001

18 Neuhauser S., Gösele P. \& Handler J. 2018. Clinical signs in late pregnant mares. Tierarztl Prax Ausg G Grosstiere Nutztiere. 46: 164-171. DOI: 10.15653/TPG-180125

19 Ohmura H. \& Jones J.H. 2017. Changes in heart rate and variability as a function of age in Thoroughbred horses. Journal of Equine Science. 28: 99-103. DOI: 10.1294/jes.28.99

20 Parraguez V.H., Coloma I., Riquelme R., Llanos A.J. \& Escobar C. 2002. Blood and physiological variables in Thoroughbred foals during the first 24 hours of life. Arquivos de Ciências Veterinárias e Zoologia da UNIPAR. 5: 169176.

21 Patteson M.W. 1996. Equine Cardiology. Oxford: Blackwell Science, pp.98-135.

22 Reed S., Bayly W. \& Sellon D. 2017. Equine Internal Medicine. 4th edn. St. Louis: Saunders Elsevier, pp.366-377.

23 Sanghavi M. \& Rutherford J.D. 2014. Cardiovascular Physiology of Pregnancy. Circulation. 130: 1003-1008. DOI: 10.1161/CIRCULATIONAHA.114.009029

24 Santarosa B.P., Lourenço M.L.G., Dantas G.N., Ulian C.M.V., Heckler M.C.T., Sudano M.J., Gonçalves R.C. \& Chiacchio S.B. 2016. Effect of pregnancy and correlation of weight and heart rate with electrocardiographic parameters in the American Miniature Horse. Arquivo Brasileiro de Medicina Veterinária e Zootecnia. 68: 579-586. DOI: $10.1590 / 1678-4162-8726$

25 Santarosa B.P., Lourenço M.L.G., Dantas G.N., Ulian C.M.V., Heckler M.C.T., Sudano M.J., Gonçalves R.C. \& Chiacchio S.B. 2016. Electrocardiographic parameters of the American Miniature Horse: influence of age and sex. Pesquisa Veterinária Brasileira. 36: 551-558. DOI: 10.1590/S0100-736X2016000600015

26 Schade J., Schade M.F.S. \& Fonteque J.H. 2014. Auscultatory and electrocardiographic characteristcs of Crioulo horses. Pesquisa Veterinária Brasileira. 34(3): 281-289. DOI: 10.1590/S0100-736X2014000300014

27 Trautvetter E., Detweiler D.K. \& Patterson D.F. 1981. Evolution of the Electrocardiogram in Young Dogs During the First 12 Weeks of Life. Journal of Electrocardiology. 14: 267-274. DOI: 10.1016/s0022-0736(81)80008-8

28 Wulf M., Erber R., Ille N., Beythien E., Aurich J. \& Aurich C. 2017. Effects of foal sex on some perinatal characteristics in the immediate neonatal period in the horse. Journal of Veterinary Behavior. 18: 37-42. DOI: 10.1016/j. jveb.2016.12.010 